\section{IEEE Xplore \\ Digital Library}

Access provided by:

Australian National University

Sign Out

Back to Results

\title{
RelCom: Relational combinatorics features for rapid object detection
}

Full Text as PDF

Full Text in HTML
2

Venkataraman, V. ; Oklahoma State Univ., Stillwater, OK, USA ; Porikli, F.

Author(s)

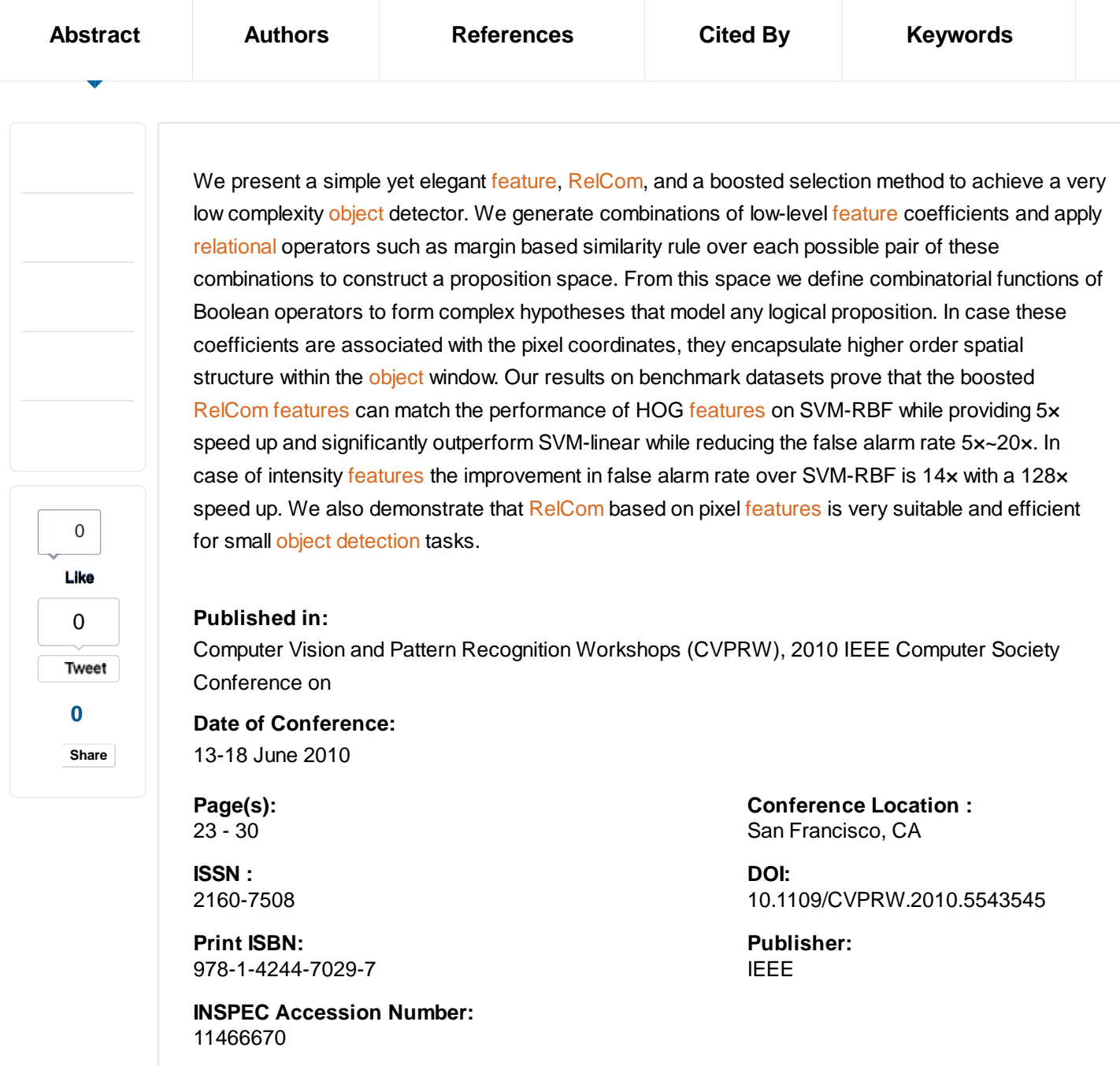

\section{IEEE Account}

Change Username/Password

Update Address
Purchase Details

Payment Options

Order History

Access Purchased Documents

\section{Profile Information \\ Communications Preferences \\ Profession and Education \\ Technical Interests}

Metrics

Similar

\section{Need Help?}

US \& Canada: +1 8006784333

Worldwide: +17329810060

Contact \& Support 
IEEE Xplore Abstract - RelCom: Relational combinatorics features for ...

C Copyright 2014 IEEE - All rights reserved. Use of this web site signifies your agreement to the terms and conditions. 